\title{
Digital Television Policy: A Squandered Opportunity
}

\section{Franco Papandrea}

$\mathrm{A}$ long with the centenary of the Australian Federation, the first of January 2001 marks the introduction of digital television in Australia. The event was unremarkable and unaccompanied by the usual fanfare and public commencement celebrations that are usually part and parcel of such occasions. There was no Prime Minister on hand, for example, to throw the switch to launch Australian television into the digital age. This was not because of a lack of opportunities to show something spectacular - imagine what a superb sight the simultaneously timed fireworks heralding the new year and the Centenary of Federation would have made on a wide-screen television set with cinema-quality pictures - but because there was virtually no reception equipment to be had by anyone wanting to watch the new digital pictures. The unavailability of reception equipment was just the latest of the negative attributes associated with a policy decision that seems to have nothing going for it. Apart from incumbent television broadcasters, who stand to reap considerable advantage from it, the decision has been widely criticised as a lemon by almost everyone.

Students or teachers seeking examples of poor public policy need look no further than any of the major broadcasting policy interventions over the past threequarters of a century. The digital television policy is merely the latest example of policy makers and regulators ignoring the axiom that efficient public policy interventions should endeavour to maximise social welfare. As outlined in Albon and Papandrea (1998), although the rhetoric accompanying major policy changes invariably pays lip service to the public interest, most of the decisions appear to be driven by an unholy coalition of political and media players intent on protecting or advancing their mutual interests. As a result, the Australian public has regularly been denied access to popular services that people in other countries had been enjoying for many years.

Free-to-air broadcasting uses the electromagnetic spectrum as the transmission medium. Because of potential interference between services broadcast on the same or adjacent channels, only a few channels can be used in any one locality. To avoid interference between services, the current Australian channel distribution pattern provides for a maximum of only six television services (of the 55 notionally available) in any one locality. Using analog transmission technology, once set the channel allocation pattern is both very difficult and very expensive to alter as a change of channels in one area sets off a

Franco Papandrea is Associate Professor of Communication and Director of the Communication and Media Policy Institute at The University of Canberra. 
chain reaction of changes in both that and other areas. To a large extent, therefore, the structure of the broadcasting industry has been predicated by historical technical considerations.

With digital broadcasting, the television industry is at the threshold of massive change. Digital delivery is much more technologically efficient than the analog system it is intended to replace. Each $7 \mathrm{MHz}$ digital channel (the same size as a current analog channel) can accommodate simultaneous broadcasting of three to four television services of a quality similar to the current analog services. Furthermore, digital broadcasting does not suffer interference problems between channels. Notionally, therefore, more than 160 standard digital television services could be accommodated in the spectrum currently reserved for television thus ending the spectrum shortage which predicated historical regulation of the industry's structure. Consequently digital conversion provided an unprecedented opportunity for the development of efficient, market-oriented industry structures that maximise economic and social benefits to society. The path chosen by the government, however, has largely squandered this unprecedented opportunity and seems set to encumber the industry with inefficient structures for decades to come.

This paper reviews the digital television policy and some suggested remedies to improve its efficiency and limit the extent of its ongoing damaging effects.

\section{History of Protectionism}

Australia has a long and unflattering history of protectionist broadcasting policy motivated by political, rather than public interest, considerations. For example, for more than three decades prior to the mid-seventies no additional metropolitan radio stations were licensed, to protect incumbents from competition (Cole, 1966; Papandrea, 2000a) and according to Myles Wright, chairman of the then regulator from 1966 to 1976, the decisions were 'very substantially influenced by political considerations' (quoted in Armstrong, 1979). Most of the more recent major policy initiatives appear to have been influenced by similar considerations. What motivates this protection of incumbents by policy makers is difficult to ascertain. But it might be conjectured that the politicians' own short-term interests are likely be better served by keeping on side powerful media proprietors who can exercise substantial influence on public opinion at subsequent elections.

The digital television decision is only the latest in a long list of major broadcasting policies that have been surrounded by controversy. While the details change, industry protection seems to be a common denominator to all of them. However, two of the major earlier policy decisions (FM radio and pay TV) are worth reviewing briefly because of their obvious parallels with the digital television policy (additional details are available in Papandrea, 2000a).

\section{FM radio}

As early as 1948 the government announced that FM radio would be introduced to provide additional $\mathrm{ABC}$ services but that its use for commercial services would be 
prohibited. After an inquiry in 1957 by the then broadcasting regulator, no services were introduced primarily because of strong opposition by incumbent broadcasters. Following a new inquiry by the regulator in 1970, the government announced its decision (in 1972) to introduce an internationally unique FM radio system. Standard receivers used overseas were not suitable for the proposed service and the intention had been to develop a special receiver for the Australian market. The announcement was followed by widespread criticism. After attracting extensive opposition and fierce criticism from the then influential Senate Standing Committee on Education, Science and the Arts, a new independent inquiry was established. Finally, following that inquiry, international standard FM radio was introduced in Australia.

Pay TV

Despite strong demand emerging as far back as the early 1970s and a recommendation for its introduction by the Australian Broadcasting Tribunal in 1982, pay television was not introduced until the 1990s. Indeed in 1986, introduction of pay television was banned for at least four years ostensibly to remove competitive pressure on regional commercial television operators then involved in the extension of commercial free-to-air services (FTAs). Pay TV services, however, were also banned in metropolitan areas not affected by the extension of regional services. A proposal to introduce a limited pay TV service delivered by satellite was announced in 1992 and was expected to be operating before the end of 1994. When an entrepreneur attempted to introduce terrestrial pay TV services using a new transmission technology, the legislation was amended to prohibit alternative services until after the establishment of the satellite service. To protect commercial FTAs, the sale of advertising or sponsorship announcements on pay TV was banned until 1 July 1997 with subscription fees required to remain the predominant source of revenue beyond that date. Additional protection prevents pay TV from obtaining exclusive rights to major sporting and other specified events that must be offered first to FTAs.

\section{Digital Television}

Broadcasting of radio and television signals uses the radiofrequency spectrum as the carrier from the broadcasting station to the consumer. With traditional (analog) technology, the image (or sound) to be broadcast is simply converted to electronic form and is then superimposed on the carrier frequency for transmission. The electronic signal varies continuously even if a still image is being broadcast. At the receiver, the carrier frequency is filtered out and the signal is then converted back to the original image. The received image, however, is prone to distortions caused by interference from various sources during broadcasting or reception.

With digital transmission, the electronic signal representing the original image is first converted to a series of binary codes representing discretely stepped 
observations of the original signal (that is, the signal is not continuously variable). The binary codes are then broadcast and are used by the receiver to reconstruct the original signal. Digital broadcasting is a more efficient user of the spectrum because substantially less of it is required to transmit discretely stepped observations than is required for analog transmissions. As the digital process facilitates compression of the broadcast signal (only changes to an image need to be transmitted to enable accurate reconstruction) efficiency in the use of the spectrum is further enhanced. The improved efficiency in spectrum use means that three to four standard digital television services can be accommodated on a conventional $7 \mathrm{MHz}$ analog channel. Alternatively, the spectrum can be used to transmit the higher levels of information needed for the broadcast of high definition (cinema quality) images or for other services.

Technically, digital transmission is capable of delivering conventional and high definition television services, several different programs (multichannelling) instead of just one per channel, interactive programs, enhanced programming allowing viewers to access alternative or complementary content to a broadcast program (for example, different camera angles in a sports program), high speed Internet services and a range of other services such as pay television, shopping channels and information services. The number of services carried by a single channel, however, depends on their bandwidth requirements. For example, the transmission of high definition television leaves little spectrum for the carriage of additional programs, enhanced or interactive programming, or for other purposes.

Another major efficiency improvement generated by digital transmission is that a television station requiring two or more transmitters (translators) at different locations to broadcast its programs throughout its licence area can use the same frequency channel for all the transmitters. With analog transmissions a different frequency channel is required to avoid interference between the transmitters. In Sydney, for example, each analog television service requires five different channels for its main transmitter and translators to distribute its analog signal, but requires only one channel to distribute a digital signal throughout the same coverage area. Furthermore, digital transmission is not prone to adjacent channel interference and thus also avoids the need of analog transmissions to maintain unused buffer channels on either side of the transmitter channel to prevent such interference. This capacity for much more intensive use of the spectrum can generate substantial efficiency gains in the use of the spectrum.

The increased spectrum efficiency of digital television (both more intensive use of the spectrum and the capacity to carry multiple programs per channel) expands prospects for the delivery of a large range of additional and new entertainment and information services to consumers. It also provides an opportunity to move beyond the current limitations on the number of free to air television services. Spectrum shortage has provided a prime justification for the licensing and regulation of commercial television services to both allocate the scarce spectrum and safeguard the community from undue influence on public opinion by the small number of possible mass services. The freeing up of spectrum would make possible the introduction of additional services in the 
market (both free-to-air and pay) with the ultimate number being determined by market demand rather than by regulators. The availability of new services would also increase diversity and reduce the influence of the small number of current operators. The number and range of services that are established would determine the extent to which regulation to promote diversity remains necessary.

These possibilities, however, have been squandered at least for most of the next decade. The government's decision on digital television ensures that the bulk of the available spectrum remains tied up in the hands of existing broadcasters with a very limited allocation to new services. Furthermore, the use of the spectrum for new services is strictly controlled by banning its use for additional commercial television services or for services likely to compete with FTAs.

\section{The Digital Decision}

The main elements of initial digital conversion decision, announced in March 1998, as it relates to television, were:

- A requirement for metropolitan FTAs to start digital transmissions by 1 January 2001, and for non-metropolitan FTAs by 1 January 2004.

- The loan to FTAs of an additional $7 \mathrm{MHz}$ channel without charge to allow the required simulcasting of programs in analog and digital formats for at least eight years.

- Mandatory transmission of a minimum level of high definition programming (subsequently set at 20 hours per week).

- Prohibition of the use of the digital spectrum for multichannelling or subscription television services by existing FTAs pending a review by 2005 . Multichanneling by national broadcasters is permitted.

- Available spectrum not required for digital conversion will be allocated competitively for the transmission of datacasting services (defined as services other than traditional television). Existing FTAs are precluded from bidding for the additional datacasting spectrum, but may use a portion of their loaned spectrum for datacasting and will be charged fees for providing the services.

- A ban on the allocation of new commercial television licences until 31 December 2006.

Seeking to justify this highly prescriptive decision the Minister for Communications (Alston, 1998) stated that while the Government 'would normally welcome additional competition, in any industry, as healthy and likely to lead to benefits for the consumer', the free-to-air and pay television industries deserved 'a degree of special treatment' because:

Australia has a world class TV system, with a strong local content component and a highly skilled production sector. This could be threatened if the existing networks had to battle a new competitor at the same time as paying huge sums to transfer to digital broadcasting, or if 
the Pay TV networks found themselves faced with significantly stronger free-to-air opponents while still trying to find their feet.

The Government's decision was widely criticised by the popular media, many independent commentators and subsequently by the Productivity Commission (2000) in the report of its Broadcasting Inquiry. The Australian Financial Review (1998a), perhaps the strongest critic at the time of the decision, labelled it 'information age mockery' and argued that it 'shackled the new information economy in the familiar old world of heavy government regulation and media-mogul politics'. Its assessment was that the

decision was not made on the basis of an open and transparent public policy review, but was designed to grant a political favour - from which it expects a political reward - to the incumbent broadcasting oligopoly.

There were also claims that the decision ignored advice from key Government Departments. According to alleged details from a 'leaked' Cabinet Submission published by The Australian Financial Review (1998b) departmental advisers argued that the decision:

- was inconsistent with 'the non interventionist approach which the Government had endorsed for developing the information economy':

- $\quad$ would 'result in inefficient use of valuable spectrum';

- would 'restrict consumer benefits from a wider range and flexibility of services';

- conferred benefits to commercial interests that 'already enjoy significant private benefits at public and community expense'; and

- 'inadequately deals with a complex and important new technology which could have far-reaching implications for the future of Australia's communications sector and its impact on the community'.

Overall, the decision represents an extraordinary level of overt protection of the interests of existing commercial television operators - extraordinary even by past standards of protection accorded to the industry.

Digital conversion is occurring at a time when rapid technological developments are transforming information and communication industries generally and are eroding the traditional technical boundaries between them. Concurrently with making alternative delivery of media services increasingly feasible, new technologies are also making prescriptive industry protection mechanisms, such as those introduced by the digital television decision, increasingly ineffective. For example, technology enabling broadband connections over existing telephone lines is already being deployed and can be used to deliver services similar to those prohibited by the digital television decision. The same technology can also provide broadband connections to the 
Internet for access to video services in other countries from sources well beyond the reach of domestic regulation. More generally, in an environment of rapid technological change, prescriptive policies are highly risky because while industry transformation is certain, how an industry will change is difficult to predict. In such an environment, efficient industry development is encouraged by less, not more, prescriptive regulation of the kind imposed by the government.

As noted by the Productivity Commission (2000:6):

The current technological revolution provides an opportunity to look forward, through the digital conversion process and beyond, in developing broadcasting policy. .... If we fail to grasp [the] opportunities to develop a convergent policy framework, Australian media and communications industries will not realise their potential. They will continue to be distorted and stunted by regulatory impediments, with adverse implications for the community and the economy generally.

\section{Ramifications of the Digital Policy}

The broadcasting spectrum is and has been a scarce and highly sought commodity. As indicated above, the development of digital technology has greatly increased the productivity and efficiency of use of the available spectrum providing the potential to accommodate a much larger range and number of services than is possible with analog technologies. The securing of this potential is the principal motivator for the conversion of television services from analog to digital. Because there is high demand for broadcasting spectrum and the services it can sustain, the rapid conversion from analog to digital is highly desirable and would produce substantial consumer benefits. Therefore, the Government's stated intention for Australia's early adoption of the new technology to '...encourage the use of television spectrum to provide a range of new information/data services' is commendable. Its attempt to prescribe the nature and range of services that are permitted, however, is condemnable.

By mandating the introduction of high definition television, prohibiting new commercial television services and strictly prescribing datacasting and multichannelling services, the digital conversion policy has serious ramifications for efficiency and social welfare. Briefly, the principal ramifications are inefficient use of spectrum, distortion of market processes, inhibition of industry development and loss of consumer welfare. Discussion of these issues follows.

\section{Inefficient Use of Spectrum}

The digital conversion policy provides for the loan of a $7 \mathrm{MHz}$ channel, free of charge, to existing FTAs to provide them with the means of implementing the mandatory transmission of a high definition signal as well as their analog signal during the simulcast period. 
The Australian broadcasting spectrum plan was designed to cater for six analog television services in any one locality, five of which are tied up for analog transmissions of commercial and national television services. As most areas already received five services (three commercial and two national) only the spectrum for the sixth planned service remained uncommitted. To implement the digital decision, spectrum had to be found for the simulcast of analog and digital signals. The channels reserved for the uncommitted sixth service thus became the primary source for transmission of the digital signal. Very little spectrum is available for other services. Scarcity is highest in Sydney where only one (possibly two) channels have been identified for potential transmission of services such as datacasting.

The transmission of a high definition signal (as well as a standard digital signal) uses up virtually the whole of the channel bandwidth. At times when the standard digital signal only is transmitted, part of the bandwidth is available for the transmission of other services. However, commercial FTAs are prohibited from using the bandwidth other than for datacasting or enhanced programs.

A more efficient use of the available spectrum would have been not to mandate high definition transmissions but to follow the approach used to introduce digital television in the United Kingdom where existing FTAs were provided with free additional spectrum sufficient to broadcast a standard digital television signal only. Had that approach been taken, two $7 \mathrm{MHz}$ channels would have been more than sufficient to enable the five existing FTAs (commercial and national) to simulcast a digital signal with their analog signal. The remaining spectrum - at least four channels - would have been sufficient to accommodate up to 12-16 additional standard digital services or other information and entertainment services, or high definition transmissions. A market mechanism could have been adopted to allocate the spectrum without constraint on its use, thus ensuring its application to the highest value use.

While it would be desirable to pursue all possible efficiency improvements, as noted by the Productivity Commission (2000), the digital decision's spectrum allocation is of 'less significance for efficiency, competition and new services than is future retention of the substantially greater spectrum now reserved for analog services'. Provided digital conversion and analog switch-off is achieved quickly, the inefficiency inherent in the current allocations would dissipate in a relatively short period of time. However, there is a substantial risk that other aspects of the digital decision, unless they are remedied, will delay analog switch-off considerably.

\section{Analog Switch-Off}

A condition of the 'free' loan of a digital channel to existing FTAs is the relinquishment of their analog spectrum at the end of the simulcast period. When digital conversion is completed, the several analog channels that are currently tied up by each FTA to broadcast its signal and avoid interference with other services will provide a sizeable boost to the spectrum that can be used for new and 
additional services. In Sydney, for example, analog switch-off will release a minimum of 25 channels for other uses and represents at least a fivefold increase in the pre-digital capacity to supply television and related services.

There is a legislated minimum simulcasting period of eight years, but no maximum period has been set. Although unstated, analog switch-off will be contingent upon a very high proportion of households having digital reception equipment. A low consumer take-up rate, therefore, will most likely prolong the simulcast period. Although digital transmissions have only just begun and consumer reaction to it is difficult to assess, several aspects of the decision strongly suggest that consumer take up of digital receivers will be both low and slow. These will be discussed below.

Some elements of the current policy provide a strong incentive to incumbent broadcasters to continue analog simulcasting for as long as possible, despite the cost of continuing analog transmissions. Although the digital decision prohibits the licensing of new commercial broadcasters before 2007, in reality the ban remains effective until the end of the simulcast period as there is no spectrum available for the purpose until then, particularly in major capital cities. By retaining their analog spectrum, incumbent operators are effectively exercising a ban on the entry of new competitors and have a strong incentive to ensure it stays in place for as long as possible. The current policy, therefore, should be amended to mitigate these incentives and prevent delays in the analog switch-off date.

\section{Digital Television and Consumers}

Mandatory transmissions of high definition programming and related audio requirements set Australia's digital television system apart from the rest of the world ${ }^{1}$. Because of its uniqueness, digital receivers, including set-top converter boxes, have to be made especially for it - receiving equipment used elsewhere in the world cannot be used here. No one is yet manufacturing receivers for use in Australia, but a major manufacturer has recently indicated it will start supplying standard digital receivers for $\$ 5000$ and high definition receivers for $\$ 8000$ later this year (Bryden-Brown, 2000). Until recently, no one was even manufacturing the set-top boxes. Faced with a launch of digital television that no one would be able to see, the incumbent broadcasters, under pressure from the Government, hastily commissioned the manufacture of a few thousand set-top boxes for use with analog television receivers. A small number arrived soon after the start of digital transmissions for distribution to major retailers as 'demonstration' units. Subsequent deliveries became available for sale to consumers at a price of $\$ 700$.

Despite the proclamations by the Government and the incumbent broadcasters, the current digital policy provides few real benefits to consumers and is thus not likely to encourage early take up of digital television (Papandrea, 2000b). At this early stage of the conversion process, it is difficult to see any

1 Apart from the high definition related requirements, the Australian standard is similar to the European standard. For historical reasons, the US system uses a different technology. 
significant incentive for rational consumers to purchase a set-top box (the only available method to receive digital signal).

A set-top box provides little more than the option of receiving the digital signal and, in some cases, a slight improvement in picture quality. Eventually, when they become available, they will also enable reception of datacasting services, program enhancements transmitted by FTAs and any multichannelling provided by the ABC and SBS. The television programs will be no different from those the existing set can receive in analog format. Quality improvements will be largely unnoticeable. Anecdotal reports from retailers indicate that most consumers cannot differentiate between analog and digital pictures (Mitchell and Grayson, 2001). Nonetheless, because the digital signal is resistant to 'snow' and 'ghosting', picture quality should improve slightly in areas prone to such reception problems. For most people, however, slight picture quality improvements alone are unlikely to be a sufficient incentive to purchase a set-top box. Indeed, in many situations, similar picture quality improvements could be achieved with the installation of an outdoor antenna at a much lower cost.

The consumer take-up of digital television, therefore, is likely to hinge on the benefits offered by new digital services. The amount and range of new digital services is severely restricted because most of the available spectrum to deliver new services has been reserved for high definition transmission. Furthermore, what is permitted is heavily regulated to prevent the new services from competing with existing television programs. The use of multichannelling by commercial broadcasters is restricted to the provision of some basic enhancements (for example, showing different camera angles in a sport program or getting additional information on items of interest in a lifestyle program) and for 'overlaps' (for example, allowing a scheduled news program to proceed concurrently with an overrunning cricket match). Datacasting is prohibited from showing anything that remotely resembles television programs. The datacasting restrictions are so extensive that major players such as News Limited, Fairfax and Telstra, that had been lobbying strongly for the introduction of datacasting, have decided not to participate in the trialing of the service. It seems unlikely, therefore, that these heavily restricted services will have sufficient appeal for widespread consumer adoption of digital television.

Purchase of a digital television set is likely to prove even less attractive to consumers. At $\$ 5000$, a standard digital set is considerably more expensive than comparable analog sets. Apart from the aesthetic appeal of not having a set-top box, a digital set will have a wide-screen format (a 16:9 rather than a 4:3 aspect ratio of analog screens). With one significant difference, its reception capabilities will be the same as those of a set-top box. The wide screen format will be fully compatible with the picture format, but not the quality, of high definition transmissions. On an analog set, a high definition picture would suffer from the so called 'envelope effect' producing a long but narrow picture across the screen much like that experienced when viewing some foreign films on SBS. The full high definition experience is available only on a high definition set with a projected price of $\$ 8000$. While there is no doubt that high definition provides an 
improved viewing experience, there is much doubt that most people will consider it to be worth the cost.

Overseas experience with consumer take-up of digital television is not encouraging. The United States (US) where high definition is encouraged, but not mandated, has experienced a low consumer take up rate. Up to the end of the third quarter of 2000, factory sales to dealers had been approximately 550,000 digital television display units and only a few thousand high definition sets with significantly fewer sales to consumers (Levy, 2000). In part this is due to the high cost of sets, particularly high definition sets. But it also partly due to the fact that digital television there offers little by way of new services other than the high definition experience. Most households in the US access their television services via cable. Through the cable systems they have access to a large number of services, including free-to-air services under 'must carry' rules. The incremental benefits of additional free-to-air services (multichannelling and datacasting are not restricted in the US and are not subject to must carry rules by cable systems) are likely to be small and demand low.

In the United Kingdom, in contrast, where free-to-air services are the main source of television programming, the use of the digital spectrum to provide additional standard (not high definition) television services, as well as facilitate the supply of a range of other services, appears to have been more successful. Rather than restricting multichannelling and other services made possible by digital technology, the UK digital system is built on promoting them. The UK Government is also eager to encourage a rapid transition to digital television and is seeking to identify and remove obstacles that may hinder progress. Competition is encouraged 'in all areas of provision in the digital TV supply chain' (OFTEL, 2000). According to the Independent Television Commission (2000), 'take-up of digital television has been driven largely by the main commercial pay television companies'. These companies have been encouraging a relatively rapid take-up of digital television by bundling the set-top box with monthly subscriptions. As at 30 June 2000, less than two years after the start of digital transmissions household penetration was 'around 20 per cent' (approximately 5 million households) and was expected to 6.5 million by the end of 2000 .

By mandating high definition television and placing extensive arbitrary restrictions on other services, the current digital policy imposes a very high opportunity cost on society for the promise of small and uncertain benefits. If only a few households are likely to want or afford high definition television, it follows that the resultant benefits to society would also be small. Alternative use of the spectrum for the development of services with much wider appeal to consumers, would undoubtedly increase the benefits to society. But such use is precluded by the mandatory requirement for high definition transmissions. Mandating of high definition television in such a situation, should be done only if there are substantial public interest reasons for doing so. But no such reasons appear to exist. The Productivity Commission (2000) says that it 'evaluated the reasons advanced for high definition and has not been convinced that any justify such a policy ...'. 
The longer the current arrangements are allowed to persist the greater will be the loss to society. It is imperative, therefore, that early amendments be made to facilitate the earliest possible conversion to digital television. In what was perhaps the most important recommendation to arise from its Broadcasting Inquiry, the Productivity Commission (2000) recommended that the digital conversion plan should be amended to:

- $\quad$ set a firm and final date (1 January 2009) to end the simulcast period in both metropolitan and regional areas;

- $\quad$ auction the analog spectrum two years earlier; and

- facilitate earlier switch-offs in areas where it becomes possible to do so.

Auctioning off of the spectrum would create a new class of owners with a direct interest in ensuring efficient use of the resource. It would also mean that incumbents would be faced with the cost of using the spectrum beyond the switchoff date if they chose to continue broadcasting their analog signal. To provide added economic incentives for incumbents and new entrants to expedite digital conversion and encourage diversity and innovation, the Commission recommended further modifications to the current arrangements to:

- Permit, not mandate, high definition television, which appears likely to become 'a premium service for a small number of viewers'. As well as increasing industry costs, it constrains development of new services, reduces consumer take-up and prolongs the conversion process.

- Allow commercial broadcasters to use digital spectrum for multichannelling and enhanced programming without restrictions. They would still be able to allocate spectrum for high definition television in the event of a high consumer demand for such a service.

- Remove arbitrary restrictions imposed on datacasters that preclude them from offering potentially valuable services likely to encourage a more rapid consumer to take-up of digital television.

These changes would encourage the industry to take full advantage of the capabilities of digital technology and develop new and innovative services in response to market demand. Consumers would also benefit from the expanded range and volume of programming likely to be available to them and would have a greater incentive for an early take-up of digital television.

\section{Conclusion}

The digital conversion policy is the latest in a long series of broadcasting policy interventions that places the private interests of incumbents well ahead of the public interest. The ramifications of this policy, however, are much more farreaching and more serious than those of earlier, similarly motivated, polices. 
With the introduction of digital technology, broadcasting is entering a new age with an unprecedented opportunity to rectify many of the inefficiencies and distortions that have been inflicted by poor policies of the past. The conversion from analog to digital transmissions enables the industry to overcome the chronic shortages of spectrum that has been used to justify most of the existing regulatory structure. Digital conversion, therefore, provides the potential for the industry to make a new start towards the development of efficient industry structures delivering services that are responsive to markets and consumer needs. The web of inefficiencies and distortions that afflicts the industry was highlighted by the Productivity Commission (2000:254) in the report of it broadcasting inquiry:

Participants have emphasised how broadcasting policy is a structure built by quid pro quos: barriers to entry are balanced against programming obligations; free to air networks are prohibited from multichannelling to help subscription services which in turn are disadvantaged by restrictions on advertising and antisiphoning rules; free to air networks are required to broadcast in high definition because they have been lent the spectrum to do so; and so on and on

It is not the time to add more quid pro quo bricks to the wall, but to take the opportunity to design a structure to serve Australians better. Greater competition, less regulation, spectrum licensing reforms, and the rapid release of spectrum are the best means of achieving this objective

According to the Productivity Commission 'without substantial changes, the digital conversion plan is at serious risk of failure'. Its report made a series of recommendations for change and provided a framework for the development of an innovative and efficient industry, responsive to consumer demands and capable of taking advantage of the many opportunities provided by digital technology. The report, however, appears to have fallen on deaf ears.

After almost a year since receiving the Commission's report, the Government is yet to announce its response to it. The signals are not positive. All subsequent Government actions relating to the digital policy suggest that the report was not to the Government's liking. There is no sign that the Government has any intention to alter the current digital conversion scheme in any way. By refusing to face to the almost certain failure of its policy, the Government is squandering the many potential economic and social benefits that other countries are set to enjoy and is condemning the industry to another generation of inefficiencies and distortions conferring substantial private benefits to powerful incumbent broadcasters.

\section{References}

Albon, R. and F. Papandrea (1998), Media Regulation in Australia and the Public Interest, Institute of Public Affairs, Melbourne. 
Alston, R., Senator the Hon Minister for Communications, the Information Economy and the Arts (1998), 'Digital: A personal message', 24 March (Media Statement 36/98).

Alston, R., Senator the Hon Minister for Communications, the Information Economy and the Arts (1999), 'Digital Broadcasting and Datacasting', Parliament House, Canberra, 21 December (Statement).

Armstrong, M (1979), 'The Broadcasting and Television Act, 1948-1976: A Case Study of the Australian Broadcasting Control Board', Chapter 6 in Tomasic, R. (ed.), Legislation and Society in Australia, The Law Foundation of New South Wales and George Allen and Unwin, Sydney.

Australian Financial Review (The) 1998a, Editorial, 25 March.

Australian Financial Review (The) 1998b, Editorial, 11 May.

Bryden-Brown, S. (2000), 'Switch to Digital TV Doesn't Rate', The Weekend Australian, 30-31 December.

Cole, B. 1966, 'What's Really Preventing the Expansion of Broadcasting Services?', The Australian Quarterly, 38(3):72-87.

Levy, J. (2000), 'Challenges and Opportunities: The US Transition to Digital Television', seminar paper presented at the University of Canberra, 29 November.

Mitchell, S. and I Grayson (2001), 'Public Tunes Out to digital Set-Top Boxes', The Australian, 9 January.

Independent Television Commission (2000), 'Joint ITC, OFTEL and OFT Advice to Government on Digital Television', London, (10 November),

http://www.itc.org.uk/documents/upl_296.doc.

OFTEL (2000), 'Joint ITC, OFTEL and OFT Advice to Government on Digital Television', London, (May), http://www.oftel.gov.uk/broadcast/digi0500.htm.

Papandrea, F. (2000a), Broadcasting Planning and Entrenched Protection of Incumbent Broadcasters, Institute of Public Affairs, Melbourne, (IPA Policy Paper 2000/1).

Papandrea, F. (2000b), 'Digital Three-Card Trick', The Institute of Public Affairs Review 52(1):12-13.

Productivity Commission (2000), Broadcasting, Report No. 11, Ausinfo, Canberra.

The author gratefully acknowledges helpful comments by the Co-editor and two anonymous referees. 